\title{
Quantitativo Microbiano em Superfícies e Equipamentos de uma Unidade de Pronto Atendimento da Região Metropolitana de Curitiba - PR
}

\author{
Microbial Quantification in Surfaces and Equipment of the Service Unit of the \\ Metropolitan Region of Curitiba - PR
}

\section{RESUMO}

Objetivo: quantificar o número de unidades formadoras de colônias por $\mathrm{cm}^{2}\left(\mathrm{UFC} / \mathrm{cm}^{2}\right)$ por meio da contagem de colônias bacterianas que se fazem presentes nas superfícies e nos equipamentos de salas de uma Unidade de Pronto Atendimento da Região Metropolitana de Curitiba - PR. Material e Métodos: trata-se de um estudo quantitativo realizado em uma Unidade Pronto Atendimento na Região Metropolitana de Curitiba - PR. Realizou-se amostragem por conveniência, sendo incluídos 14 superfícies inanimadas (bancadas, leitos) e 6 equipamentos (computadores, válvulas, desfibrilador e eletrocardiógrafo) totalizando 20 amostras. Para coleta das amostras, utilizou-se a técnica de contato que mede a carga microbiana através da placa $\operatorname{Rodac}^{\circledR}$ e para a contagem das colônias, utilizou-se o LF Equipamento (Contador de Colônias Eletrônico). Resultados: no grupo de equipamentos $66,6 \%$ corresponderam aos níveis aceitáveis de colônias; os níveis satisfatórios e não satisfatórios corresponderam ambos, a $16,6 \%$. Enquanto no grupo de superfícies os resultados apontam o mesmo percentual em níveis satisfatórios e não satisfatórios, perfazendo um total de $35,71 \%$ e $28,57 \%$ encontraram-se dentro dos níveis aceitáveis. Conclusão: os resultados do estudo apresentam valores dentro dos parâmetros pelo Protocolo de Microbiologia Ambiental do quantitativo de colônias presentes em superfícies e equipamentos. Com os resultados obtidos sugere-se que os gestores possam incorporar estratégias educacionais que visem reduzir os índices de contaminação dos profissionais que ali prestam assistência, como também da clientela assistida.

DESCRITORES: Enfermagem, Infecção hospitalar, Serviços médicos de emergência, Microbiologia, Bactérias.

\begin{abstract}
Objective: to quantify the number of Colony Forming Units per $\mathrm{cm} 2(\mathrm{CFU} / \mathrm{cm} 2)$ by counting bacterial colonies that are present on the surfaces and equipment of rooms of an Emergency Care Unit in the metropolitan region of Curitiba - PR. Material and methods: this is a quantitative study carried out in a Ready Care Unit in the metropolitan region of Curitiba - PR. Sampling was carried out by convenience, including 14 inanimate surfaces (benches, beds) and 6 equipments (computers, valves, defibrillator and electrocardiograph) totaling 20 samples. To collect the samples, the contact technique was used to measure the microbial load through the Rodac $®$ plate and for the counting of the colonies, the LF Equipment (Electronic Colony Counter) was used. Results: in the equipment group, $66.6 \%$ corresponded to acceptable levels of colonies; the satisfactory and unsatisfactory levels corresponded to $16.6 \%$. While in the group of surfaces the results indicate the same percentage in satisfactory and unsatisfactory levels, making a total of $35.71 \%$; and $28.57 \%$ were within acceptable levels. Conclusion: the results of the study presented values within the parameters by the Protocol of Environmental Microbiology of the quantitative of colonies present in surfaces and equipment. With the results obtained, it is suggested that managers can incorporate educational strategies aimed at reducing the contamination rates of the professionals who provide assistance, as well as the assisted clientele.
\end{abstract}

DESCRIPTORS: Nursing, Cross Infection, Emergency Medical Services, Microbiology, Bacteria.

1 - Docente do Centro Universitario Autônomo do Brasil, Curitiba - PR. Brasil.

2 - Enfermeira do Centro Universitario Autônomo do Brasil, Curitiba - PR. Brasil. 
$\mathrm{O}$ s atendimentos realizados em Unidades de Pronto Atendimento (UPA) têm como objetivo prestar uma assistência imediata aos pacientes em risco iminente de vida, visando à garantia de uma primeira atenção resolutiva e qualificada. Portanto, de acordo com o Ministério da Saúde (MS) na Portaria $n^{\circ} 312$, de 30 de maio de 2002, o período máximo de permanência recomendado do paciente nesse local é de até 24 horas $^{1,2}$, fato que corrobora com a Resolução CFM 2.097/14, que dispõe sobre a normatização do funcionamento da UPA (24h) e congêneres, onde em caso de internação é de responsabilidade do gestor a garantia de referência para serviço hospitalar para continuidade do tratamento ${ }^{3}$.

No entanto essa não é a realidade vivenciada no cotidiano. Denota-se, em razão do número reduzido de vagas em Unidades de Terapia Intensiva (UTI), a aglomeração de pacientes nas Salas de Emergência (SE) das UPAs, que acabam por manter pacientes em cuidados intensivos e estes são submetidos a procedimentos altamente invasivos, uso de antimicrobianos e permanência no local bem superior ao recomendado pelo MS ${ }^{1}$.

Por tratar-se de um ambiente hospitalar, as UPAs são meios importantes de proliferação e presença de bactérias multirresistentes, sendo considerado um ambiente de surtos em relação à essas bactérias, isso ocorre em virtude do perfil dos pacientes, usuários desses serviços que são mais vulneráveis em comparação as outras unidades em virtude da complexidade no atendimento ${ }^{1,4}$.

As proliferações de micro-organismos multirresistentes em ambientes de atenção à saúde vêm ganhando uma grande proporção, sendo considerada, portanto, um problema de saúde pública. Este fato é resultado de diversos fatores, tais como avanços tecnológicos relacionados aos procedimentos invasivos utilizados para diagnosticar ou tratar, técnicas realizadas de forma inadequada, baixa adesão dos profissionais de saúde às medidas de precaução padrão para controle de infecção, entre outros, o que proporciona uma predisposição para riscos de infecção ${ }^{5,6}$. O problema pode ser explicado pela utilização inadequada dos antimicrobianos, tanto na área hospitalar como na comunidade.

Nas situações de emergências verificase a inobservância e/ou a reduzida adesão aos protocolos relacionados as medidas de controle de infecção, em virtude da prioridade de manter as funções vitais do paciente. Além disso destacase a superlotação; sobrecarga de trabalho dos profissionais; ausência da distância entre leitos, o que aumenta as possibilidades do paciente desenvolver agravos relacionados à assistência ${ }^{1}$.

As disseminações dos micro-organismos advêm da contaminação cruzada, envolvendo profissionais de saúde, o paciente e o próprio ambiente do cuidado. A via mais fácil e comum de transmitir o patógeno é por meio das mãos. Geralmente, o ambiente ocupado por pacientes infectados pode tornar-se contaminado, devido à presença de bactérias e micro-organismos em superfícies inanimadas e equipamentos, servindo assim, como reservatórios secundários ${ }^{6,7}$.

Para a prevenção e controle da disseminação de micro-organismos, são necessárias ações estratégicas multidisciplinares que incidem sobre a mudança do sistema; treinamentos e monitoramentos de modo intensivo para que surja um grande potencial de sucesso em termos de melhorias da higiene, redução da carga microbiana e, consequentemente, na redução de infecções relacionados aos serviços de saúde ${ }^{8}$.

Segundo a Portaria $n^{\circ}$ 2.616/1998 do MS, o conceito de infecção hospitalar é expresso a partir do momento em que o paciente é admitido na unidade hospitalar e a infecção se desenvolve durante o período de internação ou após a alta e está relacionado com a internação ou procedimentos hospitalares $^{9}$. São definidas como sistêmicas ou locais aquelas que ocorrem após 48 horas da admissão hospitalar, após 30 dias em cirurgias sem colocação de próteses e até um 
ano após cirurgias de colocação de próteses, de acordo com as regras vigentes ${ }^{10}$.

A partir da constatação acima, a ANVISA (Agência Nacional de Vigilância Sanitária), desenvolveu o Programa de Prevenção e Controle de Infecção Hospitalar, que tem como meta diminuir as altas incidências de proliferação de micro-organismos multirresistentes ${ }^{4}$. Desta forma, considerando a relevância e a escassez de trabalhos sobre a temática, a realização de procedimentos invasivos na UPA, superlotação de pacientes, ausência de distância mínima entre um leito e outro, por exemplo, favorecem a proliferação de micro-organismos. Portanto, a amostragem e a análise dos micro-organismos presentes em superfícies possibilitam determinar se os métodos de limpeza e desinfecção utilizados são eficazes.

Diante do exposto, o estudo tem como objetivo quantificar o número de unidades formadoras de colônias por $\mathrm{cm}^{2}\left(\mathrm{UFC} / \mathrm{cm}^{2}\right)$ por meio da contagem de colônias bacterianas que se fazem presentes nas superfícies e equipamentos de salas de uma Unidade de Pronto Atendimento da Região Metropolitana de Curitiba - PR.

\section{Material e Métodos}

Trata-se de um estudo quantitativo realizado em uma UPA na Região Sul do Brasil. A coleta das amostras ocorreu após a aprovação do Comitê de Ética com o número de parecer 339.258.

A UPA atende pacientes em situações de urgência e emergência clínica e ortopédica. Apresenta setorizações distintas: sala de recepção/ espera, sanitários, sala de classificação de risco, consultórios médicos, sala de suturas/curativos, sala de inalação, farmácia, copa, administração, sala para atendimentos de emergências, sala de aplicação de medicamentos e depósitos de materiais de limpeza.

Realizou-se amostragem por conveniência, sendo incluídos 14 superfícies inanimadas (bancadas e leitos) e 6 equipamentos (computadores, válvulas, desfibrilador e eletrocardiógrafo) totalizando 20 amostras. Nos locais das superfícies foram coletadas amostras do centro geométrico e nos equipamentos coletouse no local no qual, comumente, acontecia o maior manuseio dos mesmos. As amostras foram coletadas no turno da tarde em agosto de 2014 (devido a menor demanda de atendimentos) em dia da semana definido pelo gestor da UPA.

Para coleta das amostras, utilizou-se a técnica de contato que mede a carga microbiana através da placa Rodac ${ }^{\circledR}$ (Replicated Organisms Detection and Counting), que mede $25 \mathrm{~cm}^{2}$, na qual possui meios sólidos de cultura apropriados (Microbial Contest Test Ágar). A análise dos resultados obtidos através dessa técnica serve de parâmetro básico para avaliar se a carga microbiana total se mantém nos limites estabelecidos pelas orientações normativas da Associação Nacional de Vigilância Sanitária (ANVISA).

As amostras foram coletadas nos seguintes ambientes: sala de alto risco, recepção, posto de enfermagem, farmácia, sala de prescrições médicas e de enfermagem, sala de emergência e sala de suturas. As salas escolhidas estavam sem pacientes ou não estavam em uso/atendimento no momento.

As coletas foram realizadas em superfícies inanimadas e equipamentos, onde se delimitou a área compatível com o diâmetro da placa Rodac ${ }^{\circledR}$ e o centro do material foi pressionado durante dez segundos, de acordo com a recomendação do fabricante. O material recolhido foi devidamente acondicionado em caixa térmica fechada, com controle de temperatura e encaminhado ao laboratório de microbiologia, onde foram incubados em estufa bacteriológica por um período de 24 horas à temperatura de $35 \pm 2^{\circ} \mathrm{C}$. Cada placa Rodac $^{\circledast}$ foi identificada de acordo a superfície ou equipamento onde se realizou a coleta e o setor que se encontravam.

Para a contagem das colônias, utilizouse o LF Equipamento (Contador de Colônias 
Eletrônico). O mesmo possui uma lupa e luz adequada que favorece a contagem. Após a contagem, dividiu-se o valor encontrado em cada placa por 25, com o intuito de obter o número de unidades formadoras de colônias por UFC/ $/ \mathrm{cm}^{2}$ de superfície.

\section{Resultados}

Após a realização da contagem de colônias e das UFC/ $\mathrm{cm}^{2}$ dos micro-organismos existentes nas placas Rodac $^{\circledR}$, os resultados foram comparados com o Protocolo de Microbiologia Ambiental (são expressos em unidade formadora de colônia (UFC) e quantitativo de colônias). A legislação brasileira não prevê valores-limites para a presença de micro-organismos em superfícies e equipamentos, no entanto, atua como uma espécie de controle de segurança, utilizando-se os seguintes valores para números de UFC/ $/ \mathrm{cm}^{2}$ : satisfatório < 1; aceitável 2-10 e não satisfatório > 10. Obtiveram-se então os seguintes resultados, conforme descrito na tabela 1.

Denota-se que $66,66 \%$ das amostras correspondem aos níveis aceitáveis de colônias (2-10 UFC/ $\left.\mathrm{cm}^{2}\right), 16,66 \%$ apresentaram níveis satisfatórios (<1 UFC/ $/ \mathrm{cm}^{2}$ ) e 16,66\% apresentaram-se em níveis não satisfatórios (> $10 \mathrm{UFC} / \mathrm{cm}^{2}$ ). Em números absolutos obtiveram-se então os seguintes resultados para as coletas realizadas em equipamentos: amostras dentro dos limites aceitáveis (2 a 10 $\left.\mathrm{UFC} / \mathrm{cm}^{2}\right)=4$ amostras; amostras dentro dos limites satisfatórios $\left(<1 \mathrm{UFC} / \mathrm{cm}^{2}\right)=1$ amostra e amostras com níveis não satisfatórios ( $>10$ UFC $/ \mathrm{cm}^{2}$ ) = 1 amostra.

A Tabela 2 apresenta os resultados encontrados com as coletas realizadas nas superfícies.

Em se tratando das superfícies da UPA, houve uma equivalência entre os níveis satisfatórios ( $\left.<1 \mathrm{UFC} / \mathrm{cm}^{2}\right)$ e não satisfatórios (> $10 \mathrm{UFC} / \mathrm{cm}^{2}$ ), $35,71 \%$. Para os níveis aceitáveis (2-10 UFC/ $\left.\mathrm{cm}^{2}\right)$ o percentual foi de $28,57 \%$. Em números absolutos obtiveramse os seguintes resultados para as coletas realizadas em superfícies: amostras dentro dos limites aceitáveis $\left(2-10 \mathrm{UFC} / \mathrm{cm}^{2}\right)=$ 4 amostras; amostras dentro dos limites satisfatórios $\left(<1 \mathrm{UFC} / \mathrm{cm}^{2}\right)=5$ amostras e amostras com níveis não satisfatórios ( $>10$ UFC $\left./ \mathrm{cm}^{2}\right)=5$ amostras.

Tabela 1. UFC/ $/ \mathrm{cm}^{2}$ presentes em equipamentos da Unidade de Pronto Atendimento, 2014

\begin{tabular}{|c|c|c|c|}
\hline Níveis & Equipamentos & $\begin{array}{l}\text { Número de } \\
\text { colônias }\end{array}$ & $\mathrm{UFC} / \mathrm{cm}^{2}$ \\
\hline \multirow{4}{*}{ Aceitáveis } & Desfibrilador - Sala de Emergência & 80 Colônias & 3,2 \\
\hline & $\begin{array}{l}\text { Botões de acionamento Eletrocardiógrafo - Sala de } \\
\text { Emergência }\end{array}$ & 73 Colônias & 2,92 \\
\hline & Teclado de computador - Farmácia & 70 Colônias & 2,8 \\
\hline & $\begin{array}{l}\text { Teclado de computador - Sala de prescrições médicas/ } \\
\text { enfermagem }\end{array}$ & 43 Colônias & 1,72 \\
\hline Satisfatórios & Válvula de O2 - Sala de alto risco & 9 Colônias & 0,36 \\
\hline $\begin{array}{l}\text { Não } \\
\text { Satisfatórios }\end{array}$ & Válvula do vácuo - Sala de alto risco & 300 Colônias & 12 \\
\hline
\end{tabular}


Tabela 2. UFC $/ \mathrm{cm}^{2}$ presentes em superfícies da Unidade de Pronto Atendimento, 2014

\begin{tabular}{l|l|c|c}
\multicolumn{1}{c|}{ Níveis } & \multicolumn{1}{|c}{ Superfície } & $\begin{array}{c}\text { Número de } \\
\text { Colônias }\end{array}$ & UFC/cm² \\
\hline \multirow{5}{*}{ Aceitáveis } & Mesa de computador - Farmácia & 43 Colônias & 1,72 \\
& Bancada - Posto de Enfermagem & 67 Colônias & 2,68 \\
& Bancada de prescrições - Sala de Alto Risco & 41 Colônias & 1,64 \\
& Mesa - Consultório & 63 Colônias & 2,52 \\
\hline \multirow{5}{*}{ Satisfatórios } & Bancada de medicamentos - Posto de Enfermagem & 12 Colônias & 0,48 \\
& Bancada de medicamentos - Sala de Alto Risco & 11 Colônias & 0,44 \\
& Puxador da gaveta de fios de sutura - Sala de Sutura & 5 Colônias & 0,2 \\
& Leito - Sala de Alto Risco & 11 Colônias & 0,44 \\
& Bancada da recepção & 9 Colônias & 0,36 \\
\hline \multirow{5}{*}{$\begin{array}{l}\text { Não } \\
\text { Satisfatórios }\end{array}$} & Leito - Sala de Alto Risco & 300 Colônias & 12 \\
& Maca - Sala de Sutura & 300 Colônias & 12 \\
& Maca - Consultório & 300 Colônias & 12 \\
& Bandeja (PVPI, ataduras, soros, vaselinas) - Sala de Sutura & 300 Colônias & 12 \\
& Torneira - Posto de Enfermagem & 300 Colônias & 12 \\
\hline
\end{tabular}

A soma dos resultados no que tange ao percentual de colônias presentes em superfícies e equipamentos quando analisados juntos, ficou: $30 \%$ satisfatório, $40 \%$ aceitável e $30 \%$ não satisfatório.

\section{Discussão}

Considera-se que esses equipamentos são higienizados e/ou limpados de modo insatisfatório. Segundo a recomendação do Protocolo de Microbiologia Ambiental, a correta higienização e/ou limpeza de superfícies e equipamento pode ser um fator que auxilia na redução dos focos de transmissão de microorganismos. No entanto, de acordo com a recomendação americana APHA, o valor limite para a existência das UFC's é de $2 \mathrm{UFC} / \mathrm{cm}^{2}{ }^{11}$. Mediante resultados obtidos, somente 2 das 6 amostras de equipamentos, o que corresponde à $33,33 \%$ do total, encontram-se dentro dos parâmetros considerados aceitáveis para o padrão americano.

Ao comparar os padrões das normativas brasileiras com os padrões americanos, se percebe maior rigor quanto ao quantitativo da presença de micro-organismos em equipamentos. Ao adotar padrões mais rigorosos com a existência de microorganismos nos ambientes de assistência a saúde, denota-se também a necessidade de medidas mais cautelosas e precisas para o combate do controle da infecção hospitalar, uma vez que, quanto maiores esses índices, maiores serão as taxas de morbimortalidade e, consequentemente, maiores serão os custos com a internação, exames e tratamentos ${ }^{1,8,12}$, gerando dano ao paciente e reduzindo a qualidade da assistência.

Vale destacar que os resultados obtidos neste estudo, refletem a necessidade de uma reavaliação criteriosa do processo de desinfecção 
na instituição investigada. Em relação às superfícies da UPA, subentende-se que a realização da desinfecção não ocorre de modo efetivo e eficiente, para que a presença de micro-organismos seja reduzida ao ponto de não causar possíveis danos aos usuários do serviço. Ao comparar com os padrões americanos da APHA, dentre os valores encontrados, $50 \%$ (em números absolutos, 7 das 14 superfícies) estão em consonância com sua recomendação. ${ }^{11}$

Portanto nesse sentido pesquisas nesta área contribuem de modo expressivo para a compreensão da efetividade da limpeza e/ou desinfecção das superfícies e equipamentos, pois estes são um potencial reservatório secundário de micro-organismos epidemiologicamente importantes ${ }^{13}$.

Ao somar os resultados dos equipamentos e superfícies, salienta-se que $40 \%$ do que foi analisado apresenta níveis aceitáveis de percentual de colônias. Contudo, não existe a garantia de que o ambiente está livre de uma possível contaminação cruzada, pelo contrário, provavelmente, ocorreu uma desinfecção adequada nos equipamentos e na superfície que favoreceu este resultado ${ }^{14}$. Possivelmente, se houvesse nova coleta, o resultado tenderia a ser diferente, pois a limpeza e/ou higienização perderia seu efeito, devido à recontaminação do ambiente.

Compreende-se que os percentuais obtidos por meio das amostras estão relacionados à: desinfecção inadequada, não integridade e má conservação dos equipamentos e superfícies inanimadas existentes na unidade, tais como macas, bancadas, torneira, entre outros, pois o desgaste dos mesmos ocorre, não só através do tempo de uso, como também pelo uso inadequado, manuseio incorreto e má conservação, o que consequentemente acaba favorecendo um ambiente propício à proliferação de população microbiana $^{15}$.

A contaminação advinda de superfícies inanimadas tem sido apontada como extrema relevância devido à alta prevalência de micro-organismos resistentes presentes em superfícies ambientais (leito), nos equipamentos (estetoscópios e ventiladores mecânicos) e fômites (teclado do computador e mesa de preparo de medicamentos). Esses equipamentos e superfícies são classificados como reservatórios secundários, sendo considerados como fatores responsáveis pela disseminação dos micro-organismos ${ }^{16}$.

Equipamentos de uso comum e superfícies ambientais próximas ao paciente e manuseados com frequência pelos profissionais de saúde que prestam atendimento, podem se tornar fonte de contaminação e servir como reservatórios de micro-organismos causadores de patologias. Fato esse, justificado pela participação dos profissionais de saúde como fonte de propagação de micro-organismos de importância clínica, isto é, resistentes aos antimicrobianos, favorecendo, portanto, a contaminação cruzada ${ }^{17}$.

O esclarecimento do papel do ambiente na transmissão das Infecções Relacionada à Assistência em Saúde (IRAS), merece destaque pela necessidade de múltiplas estratégias para o controle da disseminação de microorganismos resistentes a antimicrobianos. Esta é uma problemática de escala mundial que aumenta a demanda por tempo de internação, custos e morbimortalidade. Torna-se, portanto, indispensável avaliar o papel do ambiente nas infecções para levantamento de estratégias que venham a minimizar a contaminação e a disseminação de patógenos ${ }^{18}$.

Com relação ao tipo de microorganismos que possui essa característica de facilidade de transmissão cruzada e que, atualmente, incidem em adicional preocupação nas instituições de saúde em todo o mundo são: Enterococcus faecium, Staphylococcus aureus, Klebsiella pneumoniae, Acinetobacter baumannii, Pseudomonas aeruginosa e Enterobacter SP ${ }^{18-20}$.

Fica evidente que a limpeza e a desinfecção dos equipamentos e superfícies 
inanimadas são de extrema importância, porém, vale ressaltar que dificilmente essas técnicas são realizadas de modo correto. Muitos desacreditam que a aquisição de IRAS pode advir de patógenos presentes em fômites e que podem ser transmitidos para o paciente através dos próprios profissionais de saúde, que, infelizmente, não inserem em seu cotidiano técnicas aparentemente simples, mas que podem contribuir para a redução dos índices de infecções, como por exemplo, a correta antissepsia das mãos em todos os momentos que envolvam o cuidado direto e indireto ao paciente ${ }^{17}$.

Salienta-se que o presente estudo envolveu diferentes superfícies e equipamentos, o que representou uma amostra heterogênea da UPA investigada. Não é possível desconsiderar que é necessária a qualificação da equipe do Serviço de Limpeza e Desinfecção de Superfícies em Serviços de Saúde e dos Profissionais de Enfermagem. É de extrema relevância a criação da Comissão de Controle de Infecção Hospitalar, pois na UPA estudada este setor é inexistente ${ }^{13,21}$. Em geral, avaliando os estudos que envolveram o quantitativo microbiano em superfícies e equipamentos de saúde, constata-se a necessidade da condução de novos estudos para considerar uma amostra representativa em diversas UPAs.

\section{Conclusão}

O presente estudo demonstrou que $66,66 \%$ das amostras correspondem aos níveis aceitáveis de colônias; 16,66\% apresentaram níveis satisfatórios e 16,66\% apresentaramse em níveis não satisfatórios em relação aos equipamentos. Para as superfícies, ocorreu uma equivalência entre os níveis satisfatórios e não satisfatórios com $35,71 \%$, enquanto, para os níveis aceitáveis, um percentual de 28,57\%.

A soma dos resultados no que concerne ao percentual de colônias presentes em superfícies e equipamentos quando analisados juntos, ficou: $30 \%$ satisfatório, $40 \%$ aceitável e 30\% não satisfatório.

Os resultados do estudo apresentam valores dentro dos parâmetros pelo Protocolo de Microbiologia Ambiental do quantitativo de colônias presentes em superfícies e equipamentos de uma UPA, ou seja, um monitoramento satisfatório. Mas, não descarta a possibilidade da realização de um acompanhamento contínuo, haja vista que, alguns índices encontrados ainda permanecem fora dos padrões aceitáveis. Logo, medidas corretivas deverão ser tomadas, desde a conduta do profissional quanto medida de precaução, como à eficácia da desinfecção dos equipamentos e superfícies.

Espera-se que os benefícios do estudo possam ser utilizados pelos gestores e supervisores da UPA, com o intuito de incorporar estratégias educacionais que visem reduzir os índices de contaminação dos profissionais que ali prestam assistência, como também da clientela assistida nessa instituição.

\section{REFERÊNCIAS}

1. Oliveira AC, Andrade FS, Diaz MEP, Iquiapaza RA. Colonization by resistant micro-organism and infection related to helath care. Acta paul enferm. 2012; 25(2): 183-9.

2. Ministério da Saúde. Portaria n. 312 , de 2 de maio de 2002. Dispõe sobre a padronização da nomenclatura no censo hospitalar no Sistema Único de saúde. Diário oficial da República Federativa do Brasil, Brasília (DF); 2002.

3. Brasil. Conselho Federal de Medicina. Resolução CFM n. 2.097, de 17 de setembro de 2014. Dispõe sobre a normatização do funcionamento das Unidades de Pronto Atendimento (UPAs) $24 \mathrm{~h}$ e congêneres, bem como do dimensionamento da equipe médica e do sistema de trabalho nessas unidades. Brasília; 2014

4. Brasil. Agência Nacional de Vigilância Sanitária Investigação e Controle de Bactérias Multirresistentes. Brasília; 2007. 
5. Oliveira AC, Andrade FS, Diaz MEP, Iquiapaza RA. Colonization by resistant micro-organism and infection related to health care. Acta Paul Enferm. 2012; 25(2): 183-9.

6. Ferreira LA, Peixoto CA, Paiva L, Silva QCGS, Rezende $\mathrm{MP}$, Barbosa MH. Adesão às precauções padrão em um hospital de ensino. Rev Bras Enferm. 2017; 70(1): 90-7.

7. Silva ECBF, Samico TM, Cardoso RS, Rabelo MA, Neto AMB, Melo FL, et al. Colonization by staphylococcus aureus among the nursing staff of a teaching hospital in Pernambuco. Rev Esc Enferm USP. 2012; 46(1): 128-32.

8. Uneke CJ, Ndkwe CD, Oyibo PG, Nwakpu KO, Nnabu RC, Prasopa-Plaizier N. Promotion of hand hygiene strengthening initiative in a Nigerian teaching hospital: implication for improved patient safety in low-income health facilities. Braz J Infect Dis. 2014; 18(1): 21-27.

9. Figueiredo DA, Vianna RPT, Nascimento JA. Epidemiologia da infecção hospitalar em uma unidade de terapia intensiva de um hospital público municipal de João Pessoa - PB. Rev Bras Ciênc Saúde. 2013; 17(3): 233-40.

10. Ministério da Saúde. Portaria n. 2.616, de 12 de maio de 1998. Dispõe sobre organização e implementação de programas de controle de infecção hospitalar em hospitais. Brasília; 1998.

11. American Public Health Association. Ameriacan Wate Works Association, Wate Environmental Federation. Standard Methods for the examination of water and wastewater. 20a ed. Washington; 2012.

12. Oliveira AC, Paula AO, Lacerda AC, Andrade FS, Iquilapaza RA. Infecciones hospitalarias em servicio de emergência y una unidad de cuidados intensivos: similitudes y diferencias. Rev Eletrônica Enferm. 2014; 16(1): 125-31.

13. Fernando FSL, Ferreira AM, Colombro TE, Rubio FG, Almeida MTG. Fungal contamination of hospital mattresses before and following cleaning and disinfection. Acta Paul Enferm. 2013; 26(5): 485-91.

14. Mota EC, Barbosa DA, Silveira BRM, Rabelo TA, Silva NM, Silva PL, et al. Higienização das mãos: uma avaliação da adesão e da prática dos profissionais de saúde no controle das infecções hospitalares. Rev Epidemiol Control Infect. 2014; 4(1): $12-7$.
15. Oliveira, AC; Damasceno, QS. Surfaces of the hospital environment as possible deposits of resistante bactéria: a review. Rev Esc Enferm USP. 2010; 44(4): 1112-7.

16. Center for Disease Control and Prevention. National Nosocomial Infections Surveillance (NNIS) System report, data summary from January 1992 through June 2004 issued October 2004. Am j infect control. 2004; 32: 470-85

17. Silva MDM. Caracterização epidemiológica dos microrganismos presentes em jalecos dos profissionais de saúde. Rev Eletrônica Enferm. 2013; 15(1): 80-7.

18. Moraes CL, Ribeiro NFG, Costa DM, Furlan VG, Palos MAP, Vasconcelos LSNOL. Contaminação de equipamentos e superfícies de unidades de terapia intensiva de uma maternidade pública por Staphylococcus coagulase negativa. Rev Patol Trop. 2013; 42(2): 387-94.

19. Damasceno QS, Oliveira AC. O papel do ambiente hospitalar na disseminação de bactérias resistentes. Rev Epidemiol Control Infect. 2012; 2(1): 28-31.

20. Silva NO, Ferraz PC, Silva ALT, Malvezzi, Poveda VB. Avaliação da técnica de desinfecção dos colchões de uma unidade de atendimento a saúde. REME Rev Min Enferm. 2011; 15(2): 242-47.

21. Chaves LDP, Camelo SHH, Silva MR, Silva NM, Pereira AP. Hospital governance hygiene and cleaning: nurse management space. Texto Contexto Enferm. 2015; 24(4): 1166-74.

\section{CORRESPONDÊNCIA}

Cristiano Caveião

Rua Konrad Adenauer, 442; Tarumã

Curitiba - Paraná - Brasil - CEP: 82821-020

E-mail: cristiano_caveiao@hotmail.com 